\title{
In rat hepatocytes, myristic acid occurs through lipogenesis, palmitic acid shortening and lauric acid elongation
}

\author{
V. Rioux ${ }^{\dagger}$, D. Catheline and P. Legrand \\ Laboratoire de Biochimie-Nutrition Humaine, Agrocampus Rennes, INRA USC 2012, 35042 Rennes, France
}

(Received 26 January 2006; Accepted 11 April 2007)

\begin{abstract}
The origin of myristic acid in mammalian cells and the regulation of its endogenous cellular low concentration are not known. Another intriguing question is the potential metabolic properties of endogenous myristic acid as compared with exogenous myristic acid. In the present paper, we hypothesised and demonstrated that, in liver cells, in addition to the usual fatty acid synthase (FAS) pathway that produces predominantly palmitic acid and minor amounts of myristic acid, part of endogenous cellular myristic acid also comes from a shortening of palmitic acid, likely by peroxisomal $\beta$-oxidation and from lauric acid by elongation. From a nutritional point of view, C16:0 is universally found in natural fats and its shortening to myristic acid could contribute to a non-negligible source of this fatty acid (FA) in the organism. Then, we measured the distribution of endogenously synthesised myristic acid in lipid species and compared it with that of exogenous myristic acid. Our results do not support the hypothesis of different metabolic fates of endogenous and exogenous myristic acid and suggest that whatever the origin of myristic acid, its cellular concentration and lipid distribution are highly regulated.
\end{abstract}

Keywords: biosynthesis, liver, myristic acid, rats, saturated fatty acids

\section{Introduction}

Because of its negative effects on cholesterol metabolism, at high levels (Hayes and Koshla, 1992; Kris-Etherton and Dietschy, 1997), myristic acid (C14:0) has been studied when provided in the diets of animals (Koshla et al., 1997; Salter et al., 1998; Loison et al., 2002) and humans (Hughes et al., 1996; MacDougall et al., 1996; Temme et al., 1997; Dabadie et al., 2006), or when added to the medium of cultured cells (Wang et al., 1992; Rioux et al., 2000 and 2002; Kummrow et al., 2002). Additionally, data have been obtained by studying its positive effect on ( $(n-3)$ polyunsaturated fatty acid (PUFA) bioavailability (Jan et al., 2004; Dabadie et al., 2005; Rioux et al., 2005) and its specific involvement in protein $\mathrm{N}$-myristoylation (Duronio et al., 1991 and 1992; DeMar and Anderson, 1997; Rioux et al., 2006) or in trypanosome metabolism (Doering et al., 1993). However, none of these studies has determined if endogenous and exogenous myristic acids have equivalent metabolic fates.

In mammalian cells, myristic acid usually accounts for less than $1 \%$ of fatty acids (FAs) (Guillou et al., 2002; Rioux et al., 2005). Comparatively, it is particularly abundant ( $7 \%$ to $14 \%$

\footnotetext{
† E-mail: Vincent.Rioux@agrocampus-rennes.fr
}

of total FAs) in milk fat (Jensen et al., 1990). In rat mammary glands, this high level has been related to the presence of a cytosolic thioesterase II (Libertini and Smith, 1978) that releases FAs shorter than the highly predominant palmitic acid usually produced by the fatty acid synthase (FAS) complex, which is more specifically associated with thioesterase I. In other organisms, high level of myristic acid and significant activity of cytosolic thioesterase II have also been shown in a pea aphid (Ryan et al., 1982) and in the uropygial gland of some waterfowls (De Renobales et al., 1980).

In tissues other than the lactating mammary gland, however, the origin of myristic acid and the regulation of its endogenous cellular low concentration are not known. Myristic acid can come either directly from the diet, or from de novo biosynthesis, or from another tissue in which it has been synthesised and/or stored previously.

In the present paper, we demonstrate that, in liver cells, in addition to the usual FAS pathway that produces predominantly palmitic acid and minor amounts of myristic acid (Christie et al., 1981), part of endogenous cellular myristic acid can also come from a shortening of palmitic acid by peroxisomal $\beta$-oxidation and from lauric acid by elongation. The distribution of endogenously synthesised myristic acid in lipid species is analysed and compared with that of exogenous myristic acid. 


\section{Material and methods}

\section{Chemicals}

Bovine serum albumin (BSA), 4-(2-hydroxyethyl)-1-piperazine ethanesulphonic acid (HEPES), Williams' medium $E_{\text {, }}$ insulin (bovine), dexamethasone, collagenase and FAs were purchased from Sigma (St. Louis, MO, USA). Penicillinstreptomycin antibiotic mixture was provided by Eurobio (Les Ulis, France). Foetal bovine serum (FBS) was obtained from J. Boy (Reims, France). $\left[1-{ }^{14} \mathrm{C}\right]$-lauric acid was purchased from Amersham Biosciences (Les Ulis, France). $\left[1-{ }^{14} \mathrm{C}\right]$-myristic acid, $\left[9,10-{ }^{3} \mathrm{H}\right]$-palmitic acid, $\left[1-{ }^{14} \mathrm{C}\right]$ palmitic acid and $\left.{ }^{3} \mathrm{H}\right]$-acetate were from Perkin Elmer Life Sciences (Le Blanc Mesnil, France). [16- $\left.{ }^{14} \mathrm{C}\right]$-palmitic acid was from CEA (Saclay, France). Solvents and other chemicals were obtained from VWR International (Fontenay-sousBois, France). High-purity reagents for HPLC application came from Fisher Labosi (Elancourt, France). Falcon Primaria Petri culture dishes were used (AES, Combourg, France).

\section{Cultured rat hepatocytes}

The experimental protocol was in compliance with European Union guidelines for animal care and use. Sprague-Dawley male rats $(250 \mathrm{~g}$ body weight) were obtained from the breeding centre R. Janvier (Le Genest, St. Isle, France) and were food-deprived $12 \mathrm{~h}$ prior to hepatocyte preparation. Hepatocytes were obtained after perfusion of liver in situ with collagenase, as previously described (Rioux et al., 2000). The culture medium (Williams' E) was supplemented with $26 \mathrm{mmol} / / \mathrm{NaHCO}_{3} ; 12.5 \mathrm{mmol} / \mathrm{l} \mathrm{HEPES} ; 15 \mu \mathrm{mol} / / \mathrm{BSA}$; $50000 \mathrm{IU} / \mathrm{l}$ penicillin, $50 \mathrm{mg} / \mathrm{l}$ streptomycin; $1 \mu \mathrm{mol} / \mathrm{l}$ insulin and $1 \mu \mathrm{mol} / /$ dexamethasone. For plating only, the culture medium was supplemented with $7 \%(\mathrm{v} / \mathrm{v}) \mathrm{FBS}$. After plating, the cells were maintained in a humidified incubator at $37^{\circ} \mathrm{C}$ under $5 \% \mathrm{CO}_{2}$ in air. After $4 \mathrm{~h}$, the plating medium was changed to a serum-free culture medium.

\section{Incubation with radiolabelled acetate and FAs}

Hepatocytes were incubated with $\left[1-{ }^{14} \mathrm{C}\right]$-lauric acid, $\left[1-{ }^{14} \mathrm{C}\right]$ myristic acid and $\left[1-{ }^{14} \mathrm{C}\right]$-palmitic acid. $\left[1-{ }^{14} \mathrm{C}\right]$-FA/albumin complexes were prepared as previously described (Rioux et al., 2000). The final FA concentration in serum-free Williams' medium was $100 \mu \mathrm{mol} / \mathrm{l}$ with a specific activity of $183 \mathrm{MBq} /$ $\mathrm{mmol}$. After $24 \mathrm{~h}$ of culture, the medium was replaced by $2 \mathrm{ml}$ of $\left[1-{ }^{14} \mathrm{C}\right]$-FA-containing medium per dish. Incubation with $\left[9,10-{ }^{3} \mathrm{H}\right]$-palmitic acid was initiated at the same time of culture (Rioux et al., 2002) by replacing the culture medium by serum-free fresh medium containing the tritiated FA $(4 \mu \mathrm{mol} / \mathrm{l}$, $925 \mathrm{MBq} / \mathrm{mmol})$. In parallel, hepatocytes were incubated with [ ${ }^{3} \mathrm{H}$-acetate $(500 \mu \mathrm{mol} / \mathrm{l}, 732 \mathrm{MBq} / \mathrm{mmol})$.

\section{Lipid extraction and lipid species separation}

At the end of the incubation, the medium was taken off, the cells were washed and harvested in phosphate-buffered saline solution $(150 \mathrm{mmol} / \mathrm{l} \mathrm{NaCl} ; 5 \mathrm{mmol} / \mathrm{l} \mathrm{Na}$ phosphate; $\mathrm{pH}$ 7.4). After centrifugation, lipids were extracted from the cell pellet with hexane/isopropanol $(3: 2 \mathrm{v} / \mathrm{v})$ as previously described (Rioux et al., 2000). Total lipids were saponified for $30 \mathrm{~min}$ at $70^{\circ} \mathrm{C}$ by $1 \mathrm{ml}$ of $2 \mathrm{~mol} / / \mathrm{KOH}$ in ethanol. FAs were liberated by acidification and extracted with diethylether. Alternatively, lipid species from the cells and medium were separated by thin-layer chromatography (TLC) using a mixture of hexane:diethylether:acetic acid (80:20:0.5 v/v/v). Phospholipids (PL), triglycerides (TG) from the hepatocytes and TG secreted in the medium were collected and saponified as described above.

In vitro elongation and shortening assays on subcellular organelles

Peroxisomes were purified from rat liver by using the peroxisome isolation kit (Sigma), according to the procedure supplied by the producer. Microsomes were obtained from rat liver by a first centrifugation at $10000 \times \mathbf{g}\left(10 \mathrm{~min}, 4^{\circ} \mathrm{C}\right)$ followed by a second centrifugation at $100000 \times \mathbf{g}(1 \mathrm{~h}$, $4^{\circ} \mathrm{C}$ ). The resulting peroxisomal and microsomal fractions were used for palmitic acid shortening assay and lauric acid elongation assay, respectively. A $1-\mathrm{ml}$ assay mixture containing $200 \mu \mathrm{l}$ of peroxisomes (1 $\mathrm{mg}$ protein), $150 \mathrm{mmol} / \mathrm{l}$ phosphate buffer ( $\mathrm{pH} 7.16), 6 \mathrm{mmol} / \mathrm{l} \mathrm{MgCl}_{2}, 7.2 \mathrm{mmol} / \mathrm{l}$ ATP, $0.54 \mathrm{mmol} / / \mathrm{CoA}$ and $0.8 \mathrm{mmol} / \mathrm{l} \mathrm{NADPH}$ was incubated at $37^{\circ} \mathrm{C}$ for $30 \mathrm{~min}$ with $60 \mathrm{nmol}$ of $\left[16-{ }^{14} \mathrm{C}\right]$-palmitic acid $(740 \mathrm{MBq} / \mathrm{mmol})$. For elongation assay, the incubation was made with $\left[1-{ }^{14} \mathrm{C}\right]$-lauric acid in a similar mixture containing microsomes (5 $\mathrm{mg}$ protein) and malonic acid $(200 \mu \mathrm{mol} / \mathrm{l})$. The reactions were stopped by adding $1 \mathrm{ml}$ of $2 \mathrm{~mol} / / \mathrm{KOH}$ in ethanol. After $30 \mathrm{~min}$ at $70^{\circ} \mathrm{C}$, the FAs were liberated by acidification and extracted with diethylether. Control assays were run by stopping the reactions before addition of the labelled substrates.

\section{FA analysis}

FAs from each lipid extract were converted to FA naphthacyl esters as previously described (Rioux et al., 1999) and separated on HPLC (Alliance, Waters, France) with a linear gradient of methanol:acetonitrile:water, starting at 80:10:10 $(\mathrm{v} / \mathrm{v} / \mathrm{v})$ and increasing to $90: 10: 0$ in $40 \mathrm{~min}$. Elution of naphthacyl derivatives was monitored by UV absorbance at $246 \mathrm{~nm}$. Peaks corresponding to radiolabelled FAs were collected (Fraction collector, Waters), diluted with scintillation liquid (InstaFluor Plus, Perkin Elmer Life Sciences) and counted (Packard Tri-Carb 1600TR, Meriden, CT, USA).

\section{Results expression and statistical analysis}

The values reported are mean \pm s.d. $(n=3)$. Results are expressed as the per cent of the radioactivity initially added to the culture and recovered in each fraction. The cellular protein content of cell cultures, determined by a modified Lowry procedure (Bensadoun and Weinstein, 1976), was found to be homogenous for all the treatments, and is indicated in each figure legend. $P$-values were calculated using the Student $t$-test 
for two-group comparison. The differences were considered significant at a $P$-value of less than 0.05 .

\section{Results}

\section{Potential precursors for myristic acid biosynthesis}

Several potential precursors for myristic acid production were assayed with cultured rat hepatocytes (Figure 1). We first quantified the level of myristic acid produced from acetyl-CoA through the activity of FAS, by using $\left[{ }^{3} \mathrm{H}\right]$-acetate as a precursor (Figure 1a). A linear incorporation of the radioactivity was shown in the cell FA fraction, as a function of the incubation time ( 0 to $4 \mathrm{~h}$ ) and as a function of the initial concentration of acetate (50 to $500 \mu \mathrm{mol} / \mathrm{l}$, data not shown). Five radiolabelled FAs were identified (C14:0, $\mathrm{C} 16: 0, \mathrm{C18:0,C16:1} \mathrm{n-7}$ and a mixture of C18:1 n-9 and $\mathrm{n}-7)$ but only the saturated FA are presented in Figure $1 \mathrm{a}$. For all the incubation times, linear regression analyses showed that myristic acid and palmitic acid represented $10.4 \pm 3.4 \%$ and $72.5 \pm 3.2 \%$ of the radiolabelled FAs, respectively.

When the potential biosynthesis of myristic acid was measured from $\left[1-{ }^{14} \mathrm{C}\right]$-lauric acid elongation (Figure $1 \mathrm{~b}$ ), the radioactivity was rapidly and strongly recovered onto longer saturated FAs, i.e. myristic, palmitic and stearic acids. Depending on the incubation time, endogenous myristic acid represented $30.8 \pm 1.6 \%$ of the newly synthesised FAs after 30 min of incubation, and only $8.8 \pm 3.5 \%$ after $12 \mathrm{~h}$, then being elongated to endogenous palmitic acid (Figure 1b).

Finally, we measured the potential biosynthesis of myristic acid from palmitic acid shortening. Figure $1 c$ shows that $\left[9,10-{ }^{3} \mathrm{H}\right]$-palmitic acid incubation with cultured rat hepatocytes led to the biosynthesis of radiolabelled myristic acid, with other FAs obtained by elongation and desaturation of the precursor. For all the incubation times (between 3 and $12 \mathrm{~h}$ ), myristic acid arose for $9.4 \pm 1.5 \%$ of the newly synthesised FAs.

In vitro evidence for lauric acid elongation and palmitic acid shortening to myristic acid

In order to confirm the shortening of $\mathrm{C} 16: 0$ to $\mathrm{C} 14: 0$ and elongation of $\mathrm{C} 12: 0$ to $\mathrm{C} 14: 0$ in specific subcellular fractions from a crude rat liver, $\left[1-{ }^{14} \mathrm{C}\right]$-lauric acid was incubated with the microsomal fraction (Figure 2a) and $\left[16-{ }^{14} \mathrm{C}\right]$-palmitic acid with the peroxisomal fraction (Figure $2 b$ ). Figure 2 shows the radiolabelled FA separation profiles obtained by HPLC after these incubations. Evidence is presented that lauric acid elongation to myristic acid occurred in the microsomes and that palmitic acid shortening to myristic acid occurred in the peroxisomes.

\section{Comparison of endogenous and exogenous myristic acid distribution between lipid species}

The second purpose of this work was to compare the distribution of endogenously synthesised myristic acid in lipid
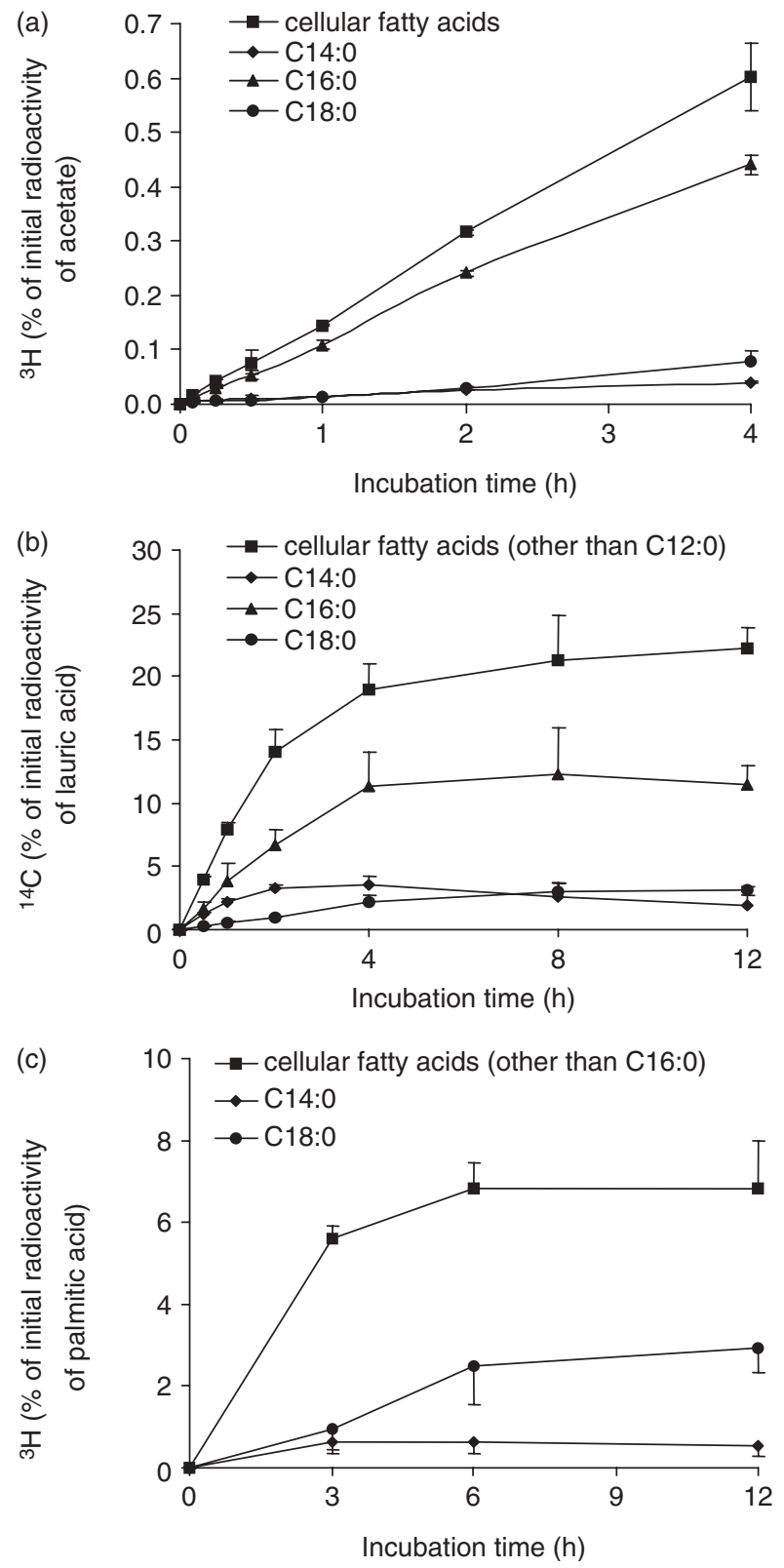

Figure 1 Endogenous biosynthesis of myristic acid from (a) acetyl-CoA, (b) lauric acid and (c) palmitic acid in cultured rat hepatocytes. Results are expressed as the per cent of the initial radioactivity added to the culture medium and recovered in cellular fatty acids. Each value is the mean \pm s.d. from three different cell cultures. The protein content was $1.46 \pm 0.25 \mathrm{mg}$ per dish for experiments with acetate, $1.46 \pm 0.36 \mathrm{mg} /$ dish for experiments with $\mathrm{C} 12: 0$ and $1.25 \pm 0.15 \mathrm{mg}$ per dish for experiments with C16:0.

species, with that of exogenous myristic acid. Figure $3 a$ shows the incorporation of myristic acid, endogenously synthesised from acetyl-CoA, in the cellular lipids and secreted TG as a function of the incubation time (0 to $4 \mathrm{~h}$ ). Most of endogenous C14:0 stayed in the cells during the incubation, i.e. $88.6 \pm 2.0 \%$ of total $\mathrm{C} 14: 0$ over $4 \mathrm{~h}$ of incubation. A detectable incorporation was however shown in secreted TG $(11.4 \pm 2.0 \%)$. In the cellular lipids, endogenous myristic acid was predominantly incorporated into 

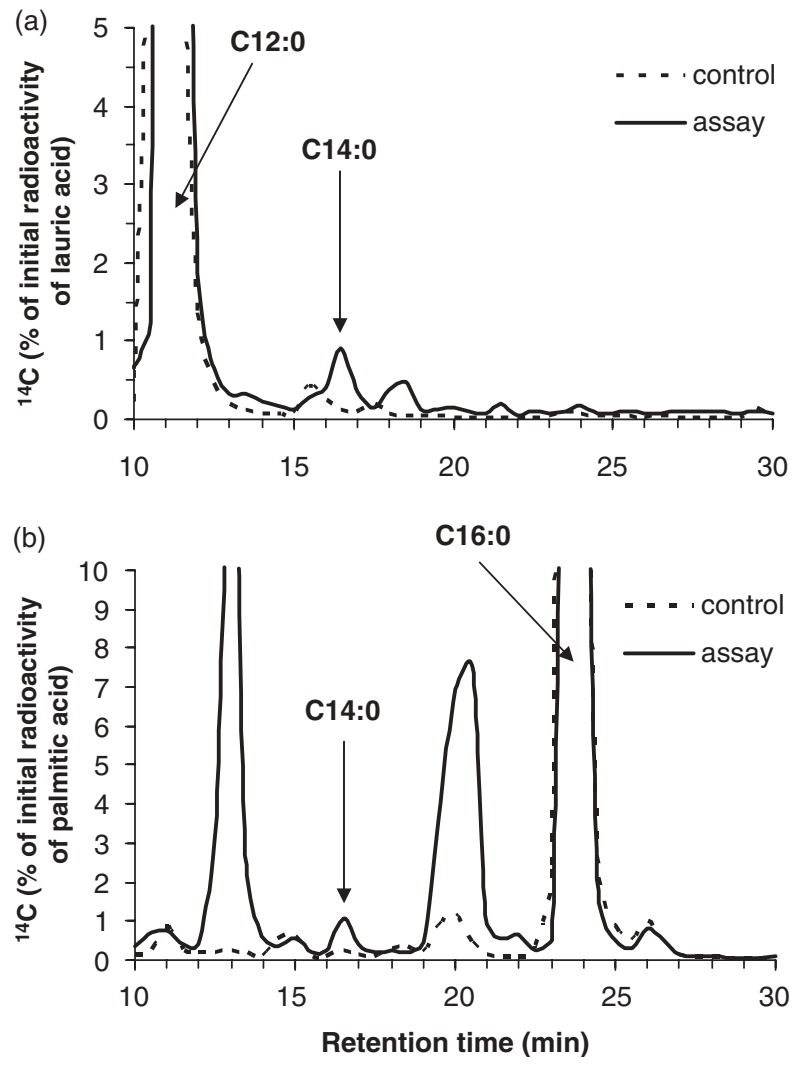

Figure 2 HPLC separation profiles of radiolabelled fatty acids obtained after (a) incubation of $\left[1{ }^{14} \mathrm{C}\right]$-lauric acid with microsomes and after (b) incubation of $\left[16-{ }^{14} \mathrm{C}\right]$-palmitic acid with peroxisomes purified from a crude rat liver. A control assay was also run by stopping the reactions before addition of the labelled substrates. After extraction and derivatisation as naphthacyl esters, radiolabelled fatty acids were identified using their retention times compared with standard fatty acids.

the TG fraction $(59.4 \pm 8.5 \%)$ and less into the PL fraction $(19.2 \pm 2.1 \%)$.

Figure $3 \mathrm{~b}$ presents a similar analysis using exogenous $\left[1-{ }^{14} \mathrm{C}\right]$-myristic acid directly incubated with cultured rat hepatocytes. The distribution in lipid species, analysed over the 4-h incubation, showed that cellular myristic acid represented $90.8 \pm 4.7 \%$ of total myristic acid. A detectable incorporation was also shown in secreted TG $(9.2 \pm 4.7 \%)$. In hepatocytes, exogenous myristic acid was predominantly incorporated into the TG fraction $(56.5 \pm 3.3 \%)$ and less into the PL fraction $(19.3 \pm 3.6 \%)$. All these values of incorporation, measured over the $4 \mathrm{~h}$ of incubation, are remarkably close and statistically similar to those obtained with endogenous myristic acid (Figure 3a).

When the lipid distribution of endogenous $\mathrm{C16}: 0$ originating from acetyl-CoA was studied (Figure 3c), palmitic acid represented $95.6 \pm 2.6 \%$ in cellular lipids and $4.4 \pm 2.6 \%$ in secreted TG, after $4 \mathrm{~h}$ of incubation. In cellular lipids, $42.0 \pm 8.0 \%$ of endogenous palmitic acid was incorporated in TG and $33.0 \pm 1.2 \%$ in PL. Figure $3 \mathrm{~d}$ presents a similar pattern using exogenous $\left[1{ }^{14} \mathrm{C}\right]$-palmitic acid directly incubated with cultured rat hepatocytes. When analysed over the $4 \mathrm{~h}$ of incubation, palmitic acid in cells represented $93.5 \pm 3.6 \%$ and palmitic acid in secreted TG $6.5 \pm 3.6 \%$ of total $\mathrm{C} 16: 0$. In cellular lipids, $47.2 \pm 2.7 \%$ of exogenous palmitic acid was incorporated into the TG fraction and $25.4 \pm 1.7 \%$ into the PL one. Comparison between the lipid distribution of endogenous and exogenous palmitic acid showed a significant difference $(P<0.05)$ in the PL incorporation (Figure $3 c$ and $d$ ).

When comparing their lipid distribution, no significant difference was shown between exogenous myristic and palmitic acids, whereas significant differences for every value were noticed between endogenous myristic and palmitic acids.

\section{Discussion}

This work was designed to study several possible pathways for the biosynthesis of myristic acid in liver cells and to compare the metabolism of endogenous and exogenous myristic acid. The first part of the present work was focused on the molecules that are potential precursors for myristic acid biosynthesis. We hypothesised that, in liver cells, part of endogenous cellular myristic acid could come from the shortening of palmitic acid by peroxisomal $\beta$-oxidation, and from the elongation of lauric acid by FA elongases. Figure 1 shows that incubation of cells with the three precursors led to the biosynthesis of cellular myristic acid. In this model, myristic acid coming from acetate represented $10 \%$ of the endogenous pool of newly synthesised FAs (Figure 1a) and palmitic acid represented more than $70 \%$. It has already been shown that palmitoyl-CoA is the main product of mammalian FAS (Chirala and Wakil, 2004). Our results are in agreement with those obtained by Lin and Smith (1978) showing that the activity of thioesterase I in liver was associated with FAS and was 10-fold less with myristoylCoA than with palmitoyl-CoA. In other tissues than liver, using $\left[1-{ }^{14} \mathrm{C}\right]$-acetate, Christie et al. (1981) have also shown that small amounts of myristic acid are synthesised by the FAS system in adipocytes (about $8 \%$ of the endogenous FAs) and higher amounts in the mammary gland (about $20 \%$ of the endogenous FAs), because of the presence of the so-called additional cytosolic type II thioesterase (Libertini and Smith, 1978).

Figure $1 \mathrm{~b}$ shows that endogenous myristic acid was also produced by elongation of lauric acid. Figure $2 \mathrm{a}$ demonstrates further that microsomes from rat liver were able to catalyse in vitro the elongation of lauric acid to myristic acid. In a previous study (Rioux et al., 2003), lauric acid elongation was suggested to produce endogenous myristic acid used for protein $\mathrm{N}$-myristoylation and $\mathrm{S}$-acylation. However, myristic acid coming from lauric acid did not stay in this form in cells since it was rapidly elongated to palmitic and stearic acid (Figure 1b). In addition, from a nutritional point of view, lauric acid is available only in a small number of dietary fats, like copra and palm oils (39\% to $54 \%$ and $44 \%$ to $51 \%$ of FAs).

Palmitic acid was finally investigated as a potential precursor for myristic acid in cultured rat hepatocytes (Figure 1c). 
(a)

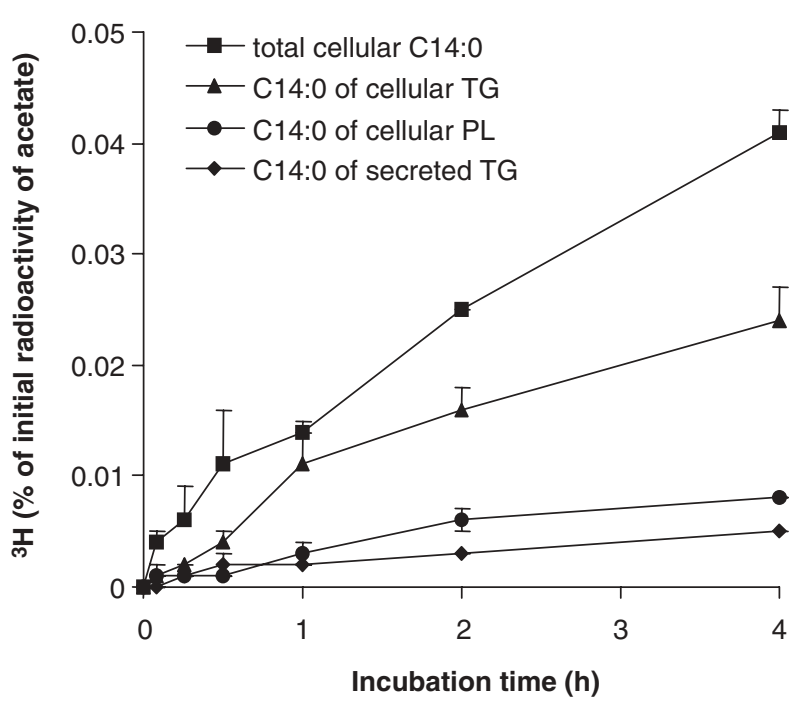

(c)

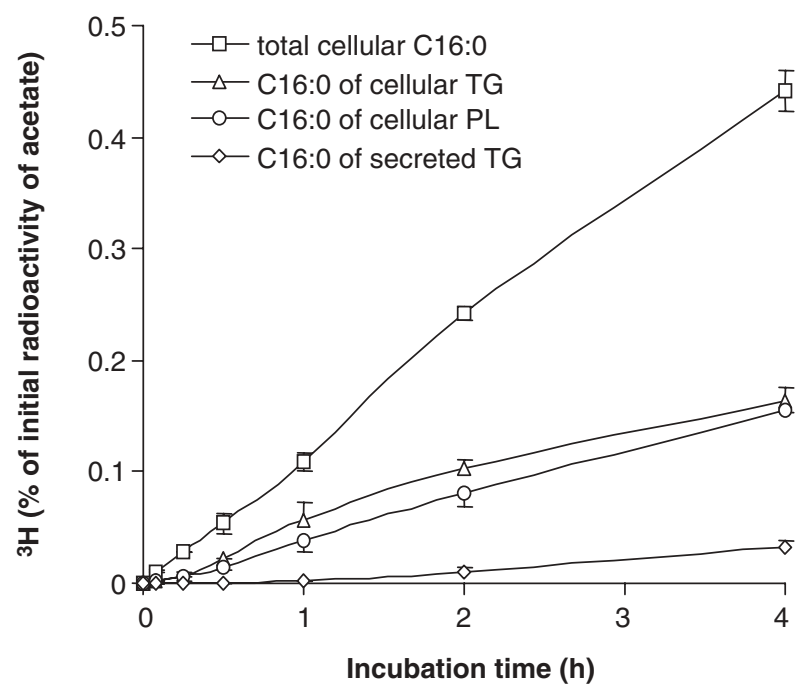

(b)

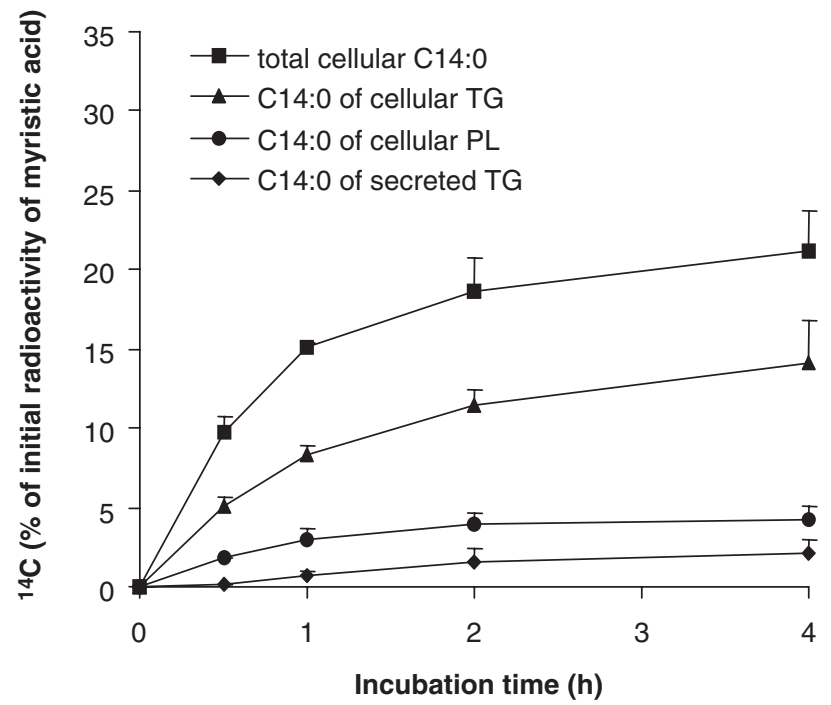

(d)

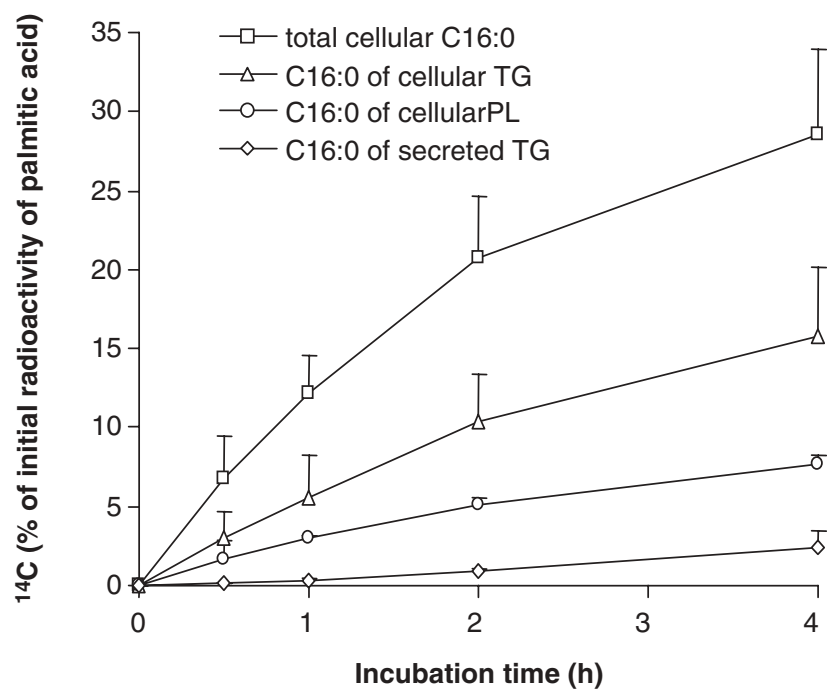

Figure 3 Distribution of radiolabelled endogenous myristic acid synthesised from (a) $\left[{ }^{3} \mathrm{H}\right]$-acetate and (b) of exogenous [1- $\left.{ }^{14} \mathrm{C}\right]$-myristic acid into cellular and secreted lipid species of cultured rat hepatocytes. Comparison is made with endogenous palmitic acid synthesised from (c) $\left[{ }^{3} \mathrm{H}\right]$-acetate and (d) $\left[1-{ }^{14} \mathrm{C}\right]$ palmitic acid incubated directly with the hepatocytes. Results are expressed as the per cent of the initial radioactivity added to the culture and recovered in each fraction. Each value is the mean \pm s.d. from three different cell cultures. The protein content was $1.46 \pm 0.25$ mg per dish for experiments with acetate, $1.26 \pm 0.40 \mathrm{mg}$ per dish for experiments with C14:0, and 1.13 $\pm 0.31 \mathrm{mg}$ per dish for experiments with C16:0.

Myristic acid was shown to represent constantly about $10 \%$ of the newly synthesised FAs coming from palmitic acid. In addition, Figure $2 \mathrm{~b}$ demonstrates that peroxisomes from rat liver were able to catalyse in vitro this shortening activity. We had previously shown (Rioux et al., 2000) in the same model that only $2 \%$ of $\mathrm{C} 16: 0$ was $\beta$-oxidised after $4 \mathrm{~h}$ incubation. Our experimental conditions $(11 \mathrm{mmol} / \mathrm{l}$ glucose and $1 \mu \mathrm{mol} / \mathrm{l}$ insulin in the medium) presumably favor lipid esterification rather than oxidation, and it is therefore unlikely that radiolabelled C14:0 (Figure 1c) comes from total $\beta$-oxidation of $\left[9,10-{ }^{3} \mathrm{H}\right]$-palmitic acid followed by de novo biosynthesis from radiolabelled acetyl-CoA. In other cell lines (CHO, BC3H1, 3T3 and P(12), incubation of $\left[9,10-{ }^{3} \mathrm{H}\right]$-palmitic acid did not lead to the identification of radiolabelled myristic acid (Wang et al., 1991 and 1992; Olson et al., 1985), except in the IM-9 cultured human lymphocytes, in which Hedo et al. (1987) have shown radiolabelled C14:0 linked to the insulin receptor, after incubation with tritiated $\mathrm{C16:0}$. Our results suggest that palmitic acid, because of its importance in natural fats, is shortened to myristic acid in the liver, which would contribute to a non-negligible portion of the synthesis of the latter in the organism, depending on the physiological status.

From a nutritional point of view however, whatever the precursors and pathways used for endogenous myristic acid biosynthesis, the amount of C14:0 produced (some hundred $\mu \mathrm{g}$ at the most, when considering a whole liver) is of far less extent relative to dietary myristic acid. Indeed, the level of myristic acid from dairy fat has been estimated up to $4 \mathrm{~g} /$ day $(4.6 \mathrm{~g} / 100 \mathrm{~g}$ total fat) in a Swedish population (Wolk et al., 2001). In the same study, it has been shown that adipose 
tissue C14:0 level (3.6\% of FAs) is a valid biomarker for dairy fat intake in men. In the rat, tissue myristic acid was also shown to be highly correlated with dietary myristic acid, especially in adipose tissue but also in the plasma and liver (Rioux et al., 2005). Under the experimental conditions used, our results suggest that de novo-synthesised myristic acid can be considered as negligible when compared to exogenous myristate.

One can therefore wonder whether endogenous and exogenous myristic acids are regulated the same way. Indeed, different metabolic pathways of exogenous and endogenous $F A s$, and different physiological influences as a function of their origins, have been demonstrated for oleate (Legrand et al., 1997), leading to the major conclusion that endogenous oleic acid coming from in situ $\Delta 9$-desaturation of stearate and exogenous dietary oleate are not equivalent in terms of TG secretion (Sampath and Ntambi, 2005). The second purpose of this work was therefore to compare the distribution of endogenously synthesised myristic acid between lipid species, with that of exogenous myristic acid. In this investigation, we studied endogenous myristic acid coming from acetyl-CoA and assumed that $\mathrm{C} 14: 0$ coming from C16:0 shortening or C12:0 elongation would behave in the same way. The results showed that similar percentages of both types of myristic acid were preferentially incorporated into cellular TG, and less into cellular PL and secreted TG (Figure $3 a$ and $b$ ). In the pea aphid in which myristic acid seemed to be almost exclusively synthesised from acetate, C14:0 was also preferentially incorporated into the TG fraction (Ryan et al., 1982). Our results do not support the hypothesis of different metabolic utilisations of endogenous and exogenous myristic acid. On the contrary, a massive uptake of exogenous myristic acid and a small de novo synthesis were metabolised in exactly the same way (Figure $3 a$ and b). By contrast, results obtained with palmitic acid (Figure $3 c$ and d) indicated that this latter was more incorporated into the PL fraction when coming from the endogenous pathway. In addition, the lipid distribution of exogenous myristic and palmitic acids was similar (Figure $3 \mathrm{~b}$ and d), whereas significant differences in the lipid incorporation were found between endogenous myristic and palmitic acids (Figure 3a and c). Therefore, compared with palmitic acid, our results suggest that the metabolism and concentration of myristic acid are highly regulated in the liver.

In conclusion, we show that in addition to the usual lipogenesis pathway, cellular myristic acid also comes from a shortening of palmitic acid by peroxisomal $\beta$-oxidation and from lauric acid by elongation. Our results suggest that whatever the origin of myristic acid, its cellular concentration and lipid distribution are highly regulated.

\section{Acknowledgments}

The authors are indebted to ARILAIT RECHERCHES (France) for constructive scientific discussion and financial support. We are grateful to M. Bouriel, K.L. Cung, R. Marion for able technical assistance and animal care and to A. Delvaux for editorial assistance.

\section{References}

Bensadoun A and Weinstein D 1976. Assay of proteins in the presence of interfering materials. Analytical Biochemistry 70, 241-250.

Chirala SS and Wakil SJ 2004. Structure and function of animal fatty acid synthase. Lipids 39, 1045-1053.

Christie WW, Hunter ML and Clegg RA 1981. The effects of cerulenin on lipid metabolism in vitro in cellular preparations from rat. Biochimica and Biophysica Acta 666, 284-290.

Dabadie H, Peuchant E, Bernard M, LeRuyet P and Mendy F 2005. Moderate intake of myristic acid in sn-2 position has beneficial lipidic effects and enhances DHA of cholesteryl esters in an interventional study. The Journal of Nutritional Biochemistry 16, 375-382.

Dabadie H, Motta C, Peuchant E, LeRuyet P and Mendy F 2006. Variations in daily intakes of myristic and $\alpha$-linolenic acids in sn-2 position modify lipid profile and red blood cell membrane fluidity. The British Journal of Nutrition 96, 283-289.

De Renobales M, Rogers L and Kolattukudy PE 1980. Involvement of a thioesterase in the production of short-chain fatty acids in the uropygial glands of mallard ducks (Anas platyrhynchos). Archives of Biochemistry and Biophysics 205, 464-477.

DeMar Jr JC and Anderson RE 1997. Identification and quantitation of the fatty acids composing the $\mathrm{CoA}$ ester pool of bovine retina, heart and liver. The Journal of Biological Chemistry 272, 31362-31368.

Doering TL, Pessin MS, Hoff EF, Hart GW, Raben DM and Englund PT 1993. Trypanosome metabolism of myristate, the fatty acid required for the variant surface glycoprotein membrane anchor. The Journal of Biological Chemistry 268, 9215-9222.

Duronio RJ, Rudnick DA, Johnson RL, Johnson DR and Gordon Jl 1991. Myristic acid auxotrophy caused by mutation of $S$. cerevisiae myristoyl-CoA: protein $\mathrm{N}$-myristoyltransferase. The Journal of Cell Biology 113, 1313-1330.

Duronio RJ, Reed SI and Gordon JI 1992. Mutations of human myristoyl CoA: protein $\mathrm{N}$-myristoyltransferase cause temperature-sensitive myristic acid auxotrophy in Saccharomyces cerevisiae. Proceedings of the National Academy of Sciences of the United States of America 89, 4129-4133.

Guillou H, Martin P, Jan S, D'Andréa S, Roulet A, Catheline D, Rioux V, Pineau T and Legrand $P$ 2002. Comparative effect of fenofibrate on hepatic desaturases in wild-type and peroxisome proliferator-activated receptor $\alpha$-deficient mice. Lipids 7, 981-989.

Hayes KC and Koshla P 1992. Dietary fatty acid thresholds and cholesterolemia. The FASEB Journal 6, 2600-2607.

Hedo JA, Collier E and Watkinson A 1987. Myristyl and palmityl acylation of the insulin receptor. The Journal of Biological Chemistry 262, 954-957.

Hughes TA, Heimberg M, Wang X, Wilcox $H$, Hughes SM, Tolley EA, Desiderio DM and Dalton JT 1996. Comparative lipoprotein metabolism of myristate, palmitate and stearate in normolipidemic men. Metabolism: Clinical and Experimental 45, 1108-1118.

Jan S, Guillou H, D'Andréa S, Daval S, Bouriel M, Rioux V and Legrand P 2004. Myristic acid increases $\Delta 6$-desaturase activity in cultured rat hepatocytes. Reproduction Nutrition Development 44, 131-140.

Jensen RG, Ferris AM, Lammi-Keefe CJ and Henderson RA 1990. Lipids of bovine and human milks: a comparison. Journal of Dairy Science 73, 223-240.

Koshla P, Hajri T, Ponczuk A and Hayes KC 1997. Decreasing dietary lauric and myristic acids improves plasma lipids more favorably than decreasing dietary palmitic acid in rhesus monkeys fed AHA step 1 type diet. The Journal of Nutrition 127, 525S-530S.

Kris-Etherton PM and Dietschy J 1997. Design criteria for studies examining individual fatty acid effects on cardiovascular disease risk factors: human and animal studies. The American Journal of Clinical Nutrition 65, 1590S-1596S.

Kummrow E, Hussain MM, Pan M, Marsh JB and Fisher EA 2002. Myristic acid increases dense lipoprotein secretion by inhibiting apoB degradation and triglyceride recruitment. Journal of Lipid Research 43, 2155-2163.

Legrand P, Catheline D, Fichot MC and Lemarchal P 1997. Inhibiting $\Delta$ 9desaturase activity impairs triacylglycerol secretion in cultured chicken hepatocytes. The Journal of Nutrition 127, 249-256.

Libertini $U$ and Smith S 1978. Purification and properties of a thioesterase from lactating rat mammary gland which modifies the product specificity of fatty acid synthetase. The Journal of Biological Chemistry 253, 1393-1401. 


\section{Rioux, Catheline and Legrand}

Lin CY and Smith S 1978. Properties of the thioesterase component obtained by limited trypsinization of the fatty acid synthetase multienzyme complex. The Journal of Biological Chemistry 253, 1954-1962.

Loison C, Mendy F, Sérougne C and Lutton C 2002. Dietary myristic acid modifies the $\mathrm{HDL}$-cholesterol concentration and liver scavenger receptor $\mathrm{BI}$ expression in the hamster. The British Journal of Nutrition 87, 199-210.

MacDougall DE, Jones PJ, Vogt J, Phang PT and Kitts DD 1996. Utilization of myristic and palmitic acid in humans fed different dietary fats. European Journal of Clinical Investigation 26, 755-762.

Olson EN, Towler DA and Glaser L 1985. Specificity of fatty acid acylation of cellular proteins. The Journal of Biological Chemistry 260, 3784-3790.

Rioux V, Catheline D, Bouriel M and Legrand P 1999. High performance liquid chromatography of fatty acids as naphthacyl derivatives. Analusis 27, 186-193.

Rioux V, Lemarchal P and Legrand P 2000. Myristic acid, unlike palmitic acid, is rapidly metabolized in cultured rat hepatocytes. The Journal of Nutritional Biochemistry 11, 198-207.

Rioux V, Galat A, Jan G, Vinci F, D'Andréa S and Legrand P 2002. Exogenous myristic acid acylates proteins in cultured rat hepatocytes. The Journal of Nutritional Biochemistry 13, 66-74.

Rioux V, Daval S, Guillou H, Jan S and Legrand P 2003. Although it is rapidly metabolized in cultured rat hepatocytes, lauric acid is used for protein acylation. Reproduction Nutrition Development 43, 419-430.

Rioux V, Catheline D, Bouriel M and Legrand P 2005. Dietary myristic acid at physiologically relevant levels increases the tissue content of C20:5 n-3 and C20:3 n-6 in the rat. Reproduction Nutrition Development 45, 599-612.
Rioux V, Beauchamp E, Pedrono F, Daval S, Molle D, Catheline D and Legrand P 2006. Identification and characterization of recombinant and native rat myristoyl-CoA protein $\mathrm{N}$-myristoyltransferases. Molecular and Cellular Biochemistry 286, 161-170.

Ryan RO, De Renobules M, Dillwith JW, Heisler CR and Blomquist GJ 1982. Biosynthesis of myristate in an aphid: involvement of a specific acylthioesterase. Archives of Biochemistry and Biophysics 213, 26-36.

Salter AM, Mangiapane EH, Bennett AJ, Bruce JS, Billett MA, Anderton KL, Marenah CB, Lawson N and White DA 1998. The effect of different dietary fatty acids on lipoprotein metabolism: concentration effects of diets enriched in oleic, myristic, palmitic and stearic acids. The British Journal of Nutrition 79, 195-202.

Sampath $\mathrm{H}$ and Ntambi JM 2005. The fate and intermediary metabolism of stearic acid. Lipids 40, 1187-1191.

Temme EHM, Mensink RP and Hornstra G 1997. Effects of medium chain fatty acids (MCFA) myristic acid and oleic acid on serum lipoproteins in healthy subjects. Journal of Lipid Research 38, 1746-1754.

Wang L, Kaduce TL and Spector AA 1991. Myristic acid utilization and processing in $\mathrm{BC}_{3} \mathrm{H} 1$ muscle cells. The Journal of Biological Chemistry 266, 13883-13890.

Wang L, Yeram NR, Kaduce TL and Spector AA 1992. Myristic acid utilization in Chinese hamster ovary cells and peroxisome-deficient mutants. Journal of Biological Chemistry 267, 18983-18990.

Wolk A, Furuheim M and Vessby B 2001. Fatty acid composition of adipose tissue and serum lipids are valid biological markers of dairy fat intake in men. The Journal of Nutrition 131, 828-833. 